\title{
Surgical Shunt Procedures in Childhood Portal Hypertension: A Review Article
}

\section{Volkan Sarper Erikci*}

Professor of Pediatric Surgery, Sağllk Bilimleri University, İzmir Faculty of Medicine, Department of Pediatric Surgery, İzmir Tepecik Health and Research Center, Turkey

*Corresponding author: Volkan Sarper Erikci, Kazım Dirik Mah, Mustafa Kemal Cad, Hakkıbey apt, No: 45 D.10 35100 Bornova-İzmir, Turkey

Received: April 21, 2021; Accepted: May 08, 2021; Published: May 15, 2021

\section{Introduction}

Normal portal pressure is between 0 and $10 \mathrm{mmHg}$ and the pressure in the portal vein is slightly higher than that of the pressure in the inferior vena cava [1]. Portal Hypertension ( $\mathrm{PH})$ is usually defined as either a hepatice venous pressure gradient greater than $5 \mathrm{mmHg}$ or hepatic venous wedge pressure greater than $10 \mathrm{mmHg}$ [2]. It is usually encountered as a complication arising from chronic liver disease and cirrhosis. Common presentation of $\mathrm{PH}$ in children include catastrophic variceal hemorrhage usually from esophagus. Other common clinical features of $\mathrm{PH}$ include splenomegaly, hypersplenism, ascites, encephalopathy, and hepatopulmonary syndrome and portopulmonary hypertension.

It has been reported that up to $15 \%$ of children with $\mathrm{PH}$ ultimately require shunt surgery [2]. Traditionally shunt surgery was a treatment option for children in whom control of variceal bleeding failed however; it was associated with relatively high rate of anastomotic stricture or thrombosis [1]. Nowadays it has also been reported that as the experience in vascular and transplant surgery together with microsurgical techniques have improved good success rates can be achieved even in small children [1]. In this review article, it is aimed to review the surgical treatment options in children with $\mathrm{PH}$ with special regard to shunt procedures under the light of relevant literature.

\section{Shunt Surgery in Children with PH}

Indications for shunt surgery in children are depicted in Table 1 $[1,3,4]$. There are variety of surgical techniques available. Common feature of all these surgical treatment options is to decrease the portal pressure in order to avoid complications of $\mathrm{PH}$ especially life threatening esophageal varices [5-8]. Portosystemic shunts may be selective or non-selective $[9,10]$.

\section{Selective Shunts}

For the sake of decompressing esophageal varices, these shunts divert blood from abdominal cavity to the low-pressure systemic venous circulation.

\section{Distal splenoreal shunt (Dean Warren shunt)}

In this kind of shunt, some portopetal blood flow is maintained in order to avoid encephalopathy. The technique includes division of splenic vein and anastomosis of distal stump into the left renal vein. Clinical importance is that after performance of distal splenorenal shunt, spleen size decreases, and hypersplenism improves and platelet and leukocyte counts normalize $[2,11,12]$. It has been reported that as the time passes selectivity in these shunts is lost and selective shunts progressively centralize $[1,10,13,14]$. Higher than $90 \%$ lon-term patency rates have been reported [1].

\section{Mesenterico-left portal bypass (Rex shunt)}

This is an example of portoportal shunt and was fist described in 1992 for a patient with portal vein trambosis following liver transplantation [14]. In this selective shunt surgery, in order to restore blood flow to the liver and bypass portal vein obstruction, a communication using a vein graft between the superior mesenteric vein and left portal vein at the level of Rex recess is constructed. Internal jugular vein is an example of these vein grafts used in these cases resulting in best results [15-18]. It has been proposed recently that this surgical option should be performed earlier in the course of the disease [1]. On the other hand in a more recent meta-analysis comprising 22 studies including 461 children with $\mathrm{PH}$ who underwent shunt surgery either with Portosystemic (PSS) shunt $(\mathrm{n}=121)$ or Rex shunt $(\mathrm{n}=340)$, it was reported that Rex shunt was associated with higher post-shunt thrombosis compared to patients who underwent porto systemic shunt surgery and it was concluded that PSS when compared to Rex shunt might offer advantages to pediatric patients with extrahepatic portal vein obstruction [19].

\section{Nonselectice Shunts}

Common feature of these shunts is the direct communication between portal system and the systemic circulation. Benefit of these shunts is the reduction of the risk of bleeding from varices but compared to selective shunts risk of hepatic encephalopathy is a significant matter.

\section{Portocaval shunt}

Direct communication between the portal and systemic circulation in this shunt is performed by the direct anastomosis of lower stump of portal vein after closure near to the liver to the inferior vena cava. Full diversion of blood flow within the portal system to the systemic circulation can be obtained by this surgical intervention but the risk of hepatic encephalopathy is again a significant risk.

\section{Proximal splenorenal shunt}

In this shunt procedure, spleen is removed after the splenic vein is divided. Anastomosis between the splenic vein stump and left renal vein is performed end-to-side in fashion [20]. Postsplenectomy sepsis is a major concern in this kind of porto-systemic shunt together with shunt stenosis and thrombosis. Intraperitoneal adhesions and propagation of the thrombosis in the splenic vein into the portal venous system may exacerbate $\mathrm{PH}$. Liver transplantation if necessary 
Table 1: Indications for shunt surgery in children with $\mathrm{PH}$.

\begin{tabular}{|l|}
\hline Uncontrolled bleeding from esophageal varices. ${ }^{*}$ \\
\hline Bleeding from gastric or ectopic varices. \\
\hline Hypersplenism or massive splenomegaly. \\
\hline Isolated extrahepatic portal vein obstruction. \\
\hline Lack of access to endoscopy. \\
\hline Symptomatic biliary obstruction due to choledocal varices. \\
\hline Neurological impairment \\
\hline Patient choice \\
\hline
\end{tabular}

*No response to at least 2 sessions of endoscopic treatment.

in future may also be jeopardized.

\section{Mesocaval shunt}

The usual mesocaval shunt is an "H" type interpositional graft using a prosthetic conduit such as Dacron/GoreTex (Drapanas shunt) or autologous vein graft although this kind of shunt may also be performed direct side-to-side mesocaval anastomosis after a sufficient mobilization of both superior mesenteric vein and inferior vena cava $[1,21]$. Auvert shunt is another variant of mesocaval shunt using anastomosis between iliac veins and superior mesenteric vein [22] Other nonselective shunts include Sarfeh and Mitra shunts. In Sarfeh shunt a GoreTex graft is used after massive collateral ligation while in Mitra shunt a side-to-side splenorenal anastomosis is performed preserving spleen and the anastomosis is performed between splenic vein and left renal vein $[1,7]$

\section{Conclusion}

In conclusion, the spectrum of surgical shunts in children with $\mathrm{PH}$ has a wide range. All of these procedures focus on the prevention of catastrophic variceal hemorrhage usually from esophagus. Nonselective shunts have the risk of postoperative encephalopathy. Although Rex shunt has a benefit of maintaining the physiologic portal venous flow through the liver, it has been suggested that portosystemic shunts, even if they have higher stenosis rate but lower thrombosis rate with regard to Rex shunts, may be a useful treatment option in children with extrahepatic portal vein obstruction and the long-term outcome of children with $\mathrm{PH}$ will be better than those previous cases.

\section{References}

1. De Ville de Goyet J, D'Ambrosio G, Grimaldi C. Surgical management of portal hypertension in children. Semin Pediatr Surg. 2012; 21: 219-232.

2. Patel N, Loveland J. Surgery for portal hypertension in children: a 12-year review. S Afr Med. J. 2017; 107: 12132.

3. Botha JF, Campos BD, Grant WJ, et al. Portosystemic shunts in children: a 15-year experience. J Am Coll Surg. 2004; 199: 179-185.

4. Bambini DA, Superina R, Almond PS, Whitington PF, Alonso E. Experience with the Rex shunt (mesenterico-left portal bypass) in children with extrahepatic portal hypertension. J Pediatr Surg. 2000; 35: 13-18.

5. Gauthier F, De Dreuzy O, Valayer J, et al. H-type shunt with an autologous venous graft for treatment of portal hypertension in children. J Pediatr Surg. 1989; 24: 1041-1043.

6. Altman RP. Portal decompression by interposition mesocaval shunt in patients with biliary atresia. J Pediatr Surg. 1976; 11: 809-814.

7. Mitra SK, Mukherjee B, Prasad GR, et al. Extrahepatic portal obstruction in children-Experience with side-to-side lienorenal shunt without splenectomy. Indian J Pediatr. 1983; 50: 55-60.

8. Bismuth H, Franco D. Portal diversion for portal hypertension in early childhood. Ann Surg. 1976; 183: 439-446.

9. Milleti E, Rosenthal P. Management of portal hypertension in children. Curr Gastroenterol Rep. 2011; 13: 10-16.

10. Scholz E, Sharif K. Surgery for portal hypertension in children. Curr Gastroenterol Rep. 2011; 13: 279-285.

11. Shilyansky J, Roberta EA, Superina RA. Distal splenorenal shunts for the treatment of severe thrombocytopenia from portal hypertension in children. J Gastrointest Surg. 1999; 3: 167-172.

12. Eizaguirre I, Tovar JA, Orcolaga G, et al. Warren's shunt in the treatment of portal hypertension in children. Cir Pediatr. 1991; 4: 134-139.

13. Superina RA, Alonso EM. Medical and surgical management of portal hypertension in children. Curr Treat Options Gastroenterol. 2006; 9: 432-443.

14. Di Francesco F, Grimaldi C, De Ville de Goyet J. Meso-Rex bypass - a procedure to cure prehepatic portal hypertension: the insight and inside. J Am Coll Surg. 2014; 218: e23-e36.

15. De Ville de Goyet J, Gibbs P, Clapuyt P, et al. Original extrahilar approach for hepatic portal revascularization and relief of extrahepatic portal hypertension related to later portal vein thrombosis after pediatric liver transplantation: Iong term results. Transplantation. 1996; 62: 71-74.

16. De Ville de Goyet J, Alberti D, Clapuyt P, et al. Direct bypassing of extrahepatic portal venous obstruction in children: a new technique for combined hepatic portal revascularization and treatment of extrahepatic portal hypertension. J Pediatr Surg. 1998; 33: 597-560.

17. Krebs-Schimitt D, Briem-Richter A, Grabhorn E, et al. Effectiveness of Rex shunt in children with portal hypertension following liver transplant or with primary portal hypertension. Pediatr Transplant. 2009; 13: 540-544.

18. Sharif K, McKiernan P, de Ville de Goyet, et al. Mesoportal bypass for extrahepatic portal vein obstruction in children: close to a cure for most! J Pediatr Surg. 2010; 45: 272-276.

19. Zielsdorf S, Narayanan L, Kantymyr S, et al. Surgical shunts for extrahepatic portal vein obstruction in pediatric pateints: a systematic review. HPB. 2020.

20. Prasad AS, Gupta S, Kohli V, et al. Proximal splenorenal shunts for extrahepatic portal venous obstruction in children. Ann Surg. 1994; 219: 193 196.

21. Drapanas T, LoCicero J, Dowling B. Hemodynamics of the interposition mesocaval shunt. Ann Surg. 1975; 181: 523-531.

22. Rypins EB, Sarfeh IJ. Partial portal decompression: two approaches to the management of portal hypertension. Hepatology. 1990; 12: 370-372. 